ERRATA

\title{
MELT PROCESSING OF YBaCuO SUPERCONDUCTORS AND CRITICAL CURRENTS
}

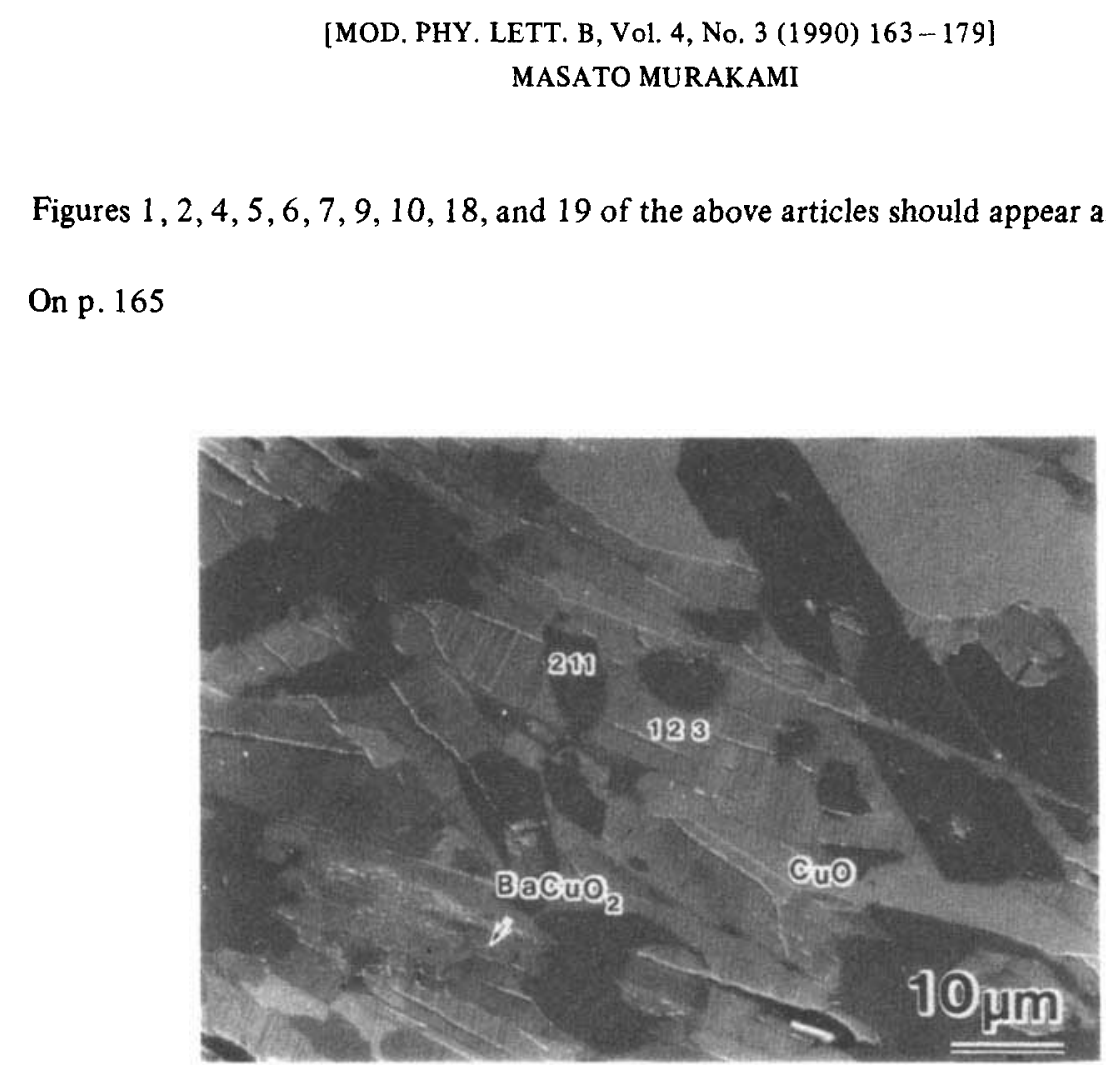

Fig. 1. Microstructure of $\mathrm{YBaCuO}$ cooled slowly from $1200^{\circ} \mathrm{C}$. 
On p. 165

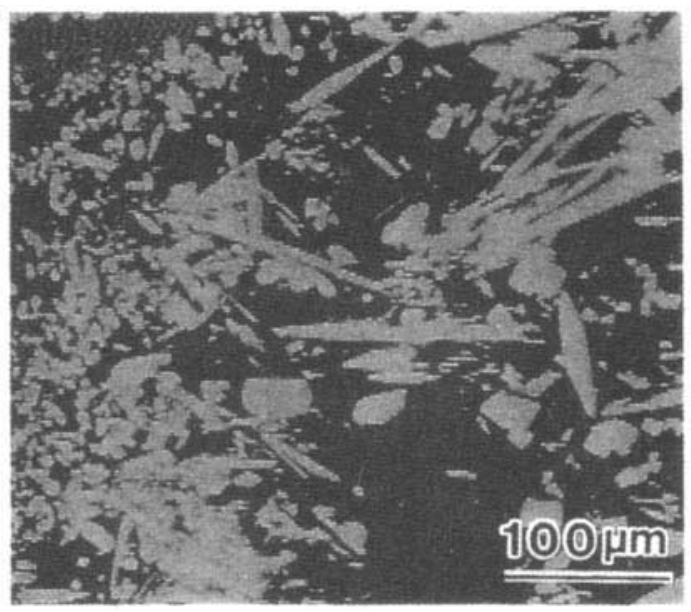

Fig. 2. Microstructure of $\mathrm{YBaCuO}$ cooled slowly from $1200^{\circ} \mathrm{C}$ to $1000^{\circ} \mathrm{C}$ and quenched. The distribution of 211 phase in the liquid is shown.

On p. 167

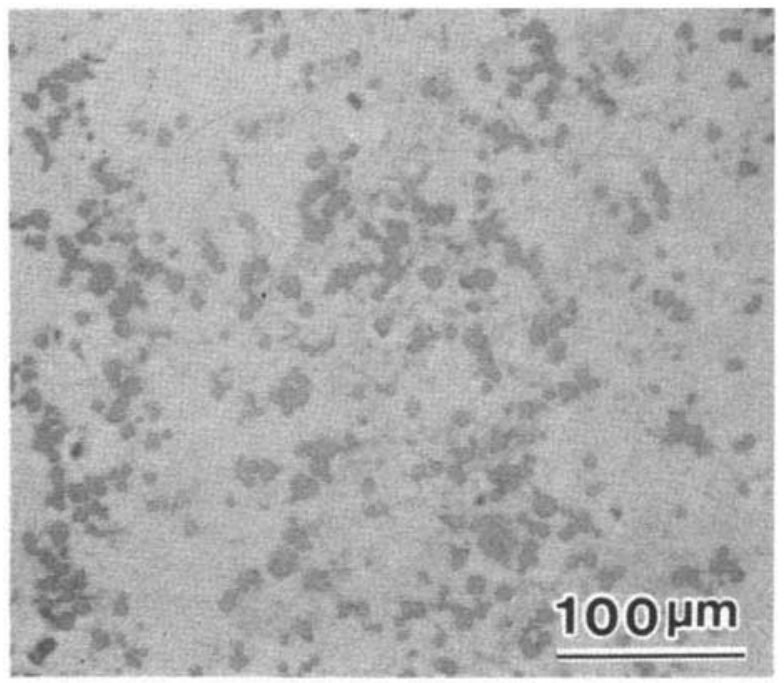

Fig. 4. Microstructure of $\mathrm{YBaCuO}$ rapidly heated to $1450^{\circ} \mathrm{C}$ and held for 3 minutes and quenched. The distribution of $\mathrm{Y}_{2} \mathrm{O}_{3}$ is shown in the figure. 
On p. 167

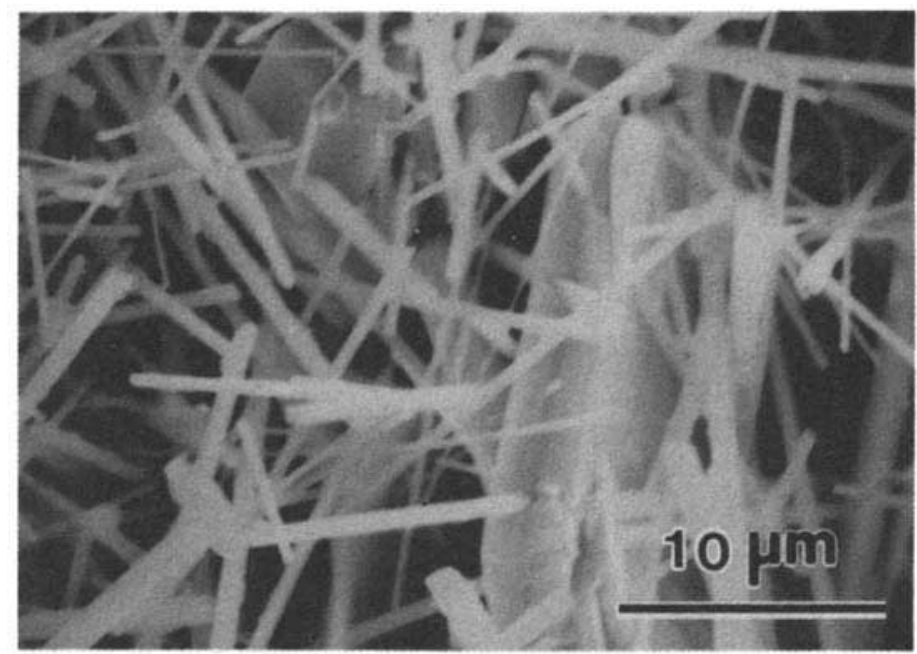

Fig. 5. Scanning electron micrograph for the fracture surface of $\mathrm{YBaCuO}$ reheated to the $211+L$ region. The morphology of 211 nucleated from the $\mathrm{Y}_{2} \mathrm{O}_{3}$ is shown.

On p. 168

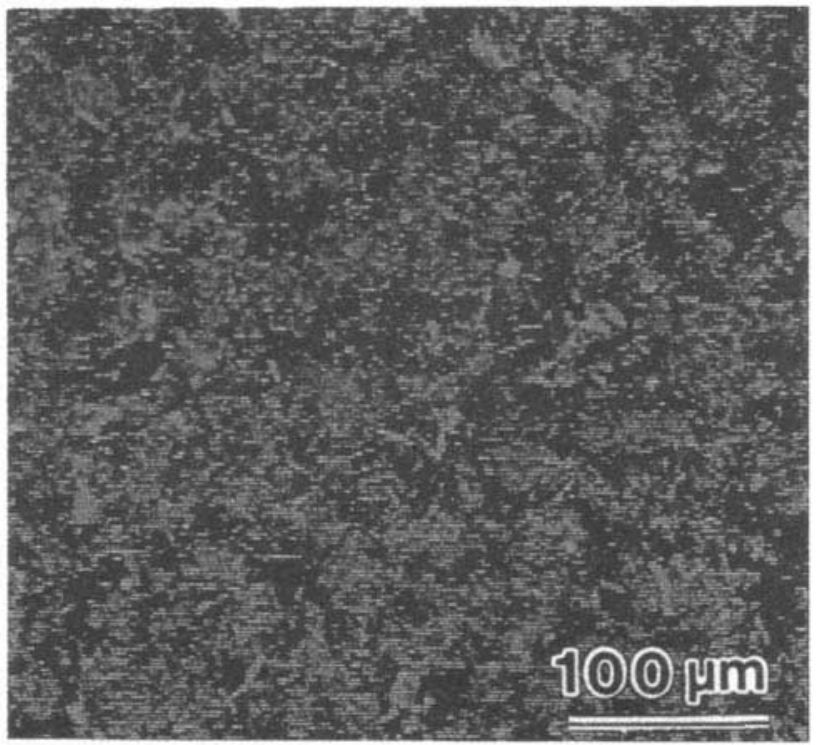

Fig. 6. Microstructure of $\mathrm{YBaCuO}$ quenched from $1450^{\circ} \mathrm{C}$ and reheated to the $211+L$ region and cooled down to $1000^{\circ} \mathrm{C}$. Note that $211^{\prime}$ 's distribution is more uniform and its size is much finer than that presented in Fig. 2. 
436 M. Murakami

On p. 169

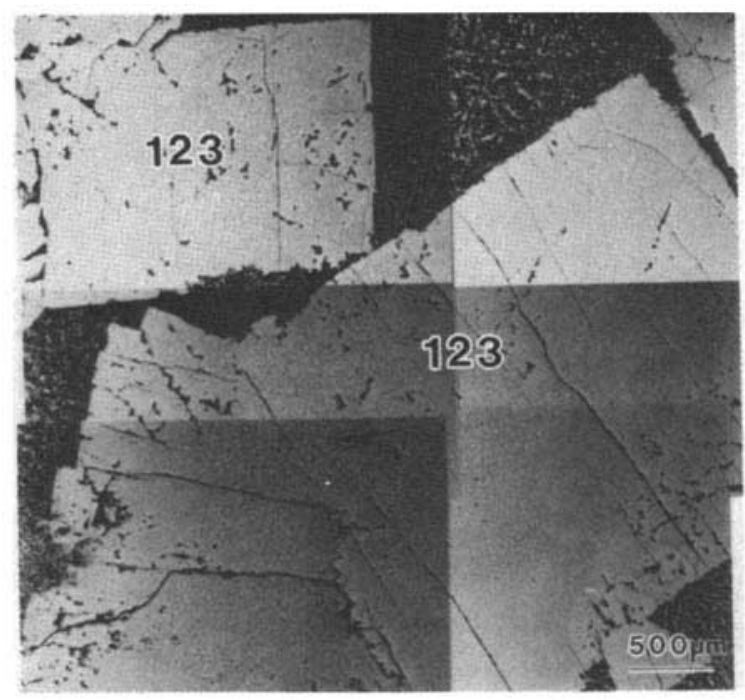

Fig. 7. Large $\mathrm{YBa}_{2} \mathrm{Cu}_{3} \mathrm{O}_{y}$ crystals grown from precursor microstructure shown in Fig. 6.

On p. 170

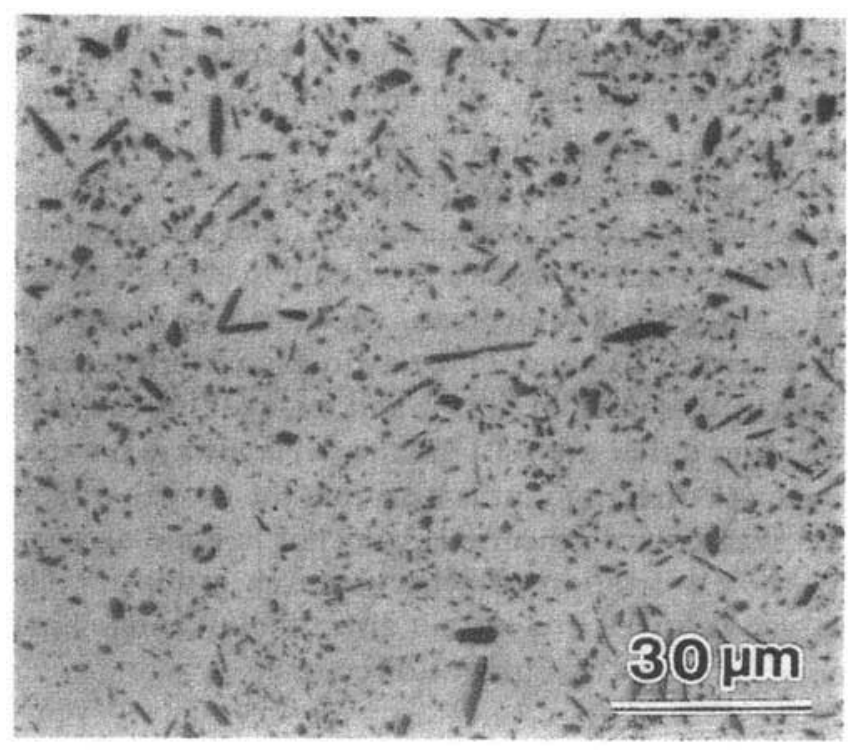

Fig. 9. Optical micrograph for QMG processed YBaCuO. Note that the sample contains fine 211 inclusions observed as dark spots in the figure. 
On p. 171

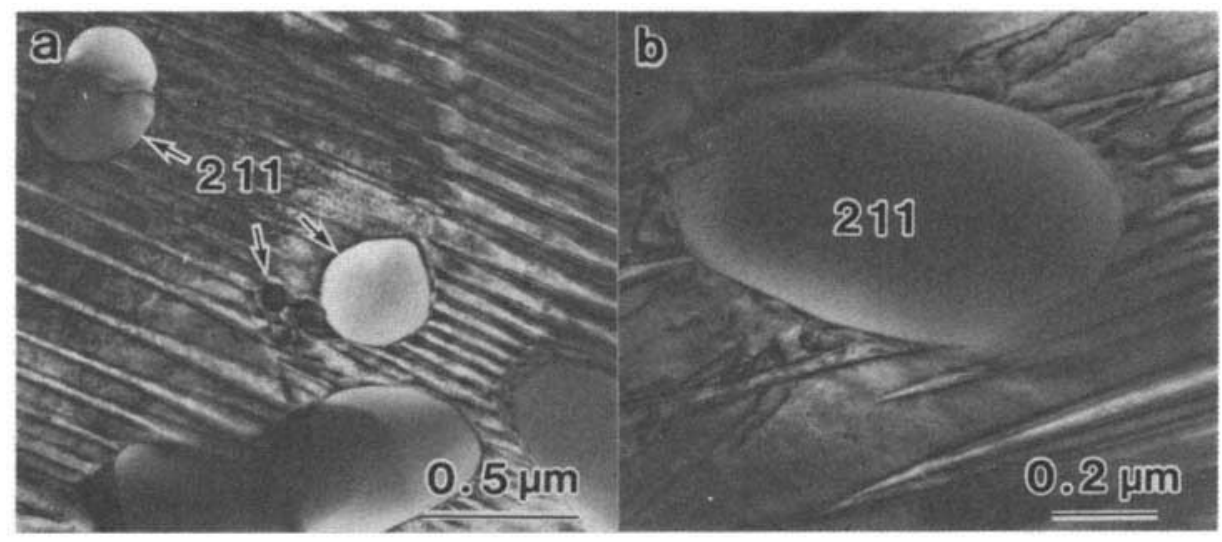

Fig. 10. Transmission electron micrograph for $\mathrm{QMG}$ processed $\mathrm{YBaCuO}$. Although twins are not observed through optical microscopic observation, the presence of dense twin structures is confirmed.

On p. 178

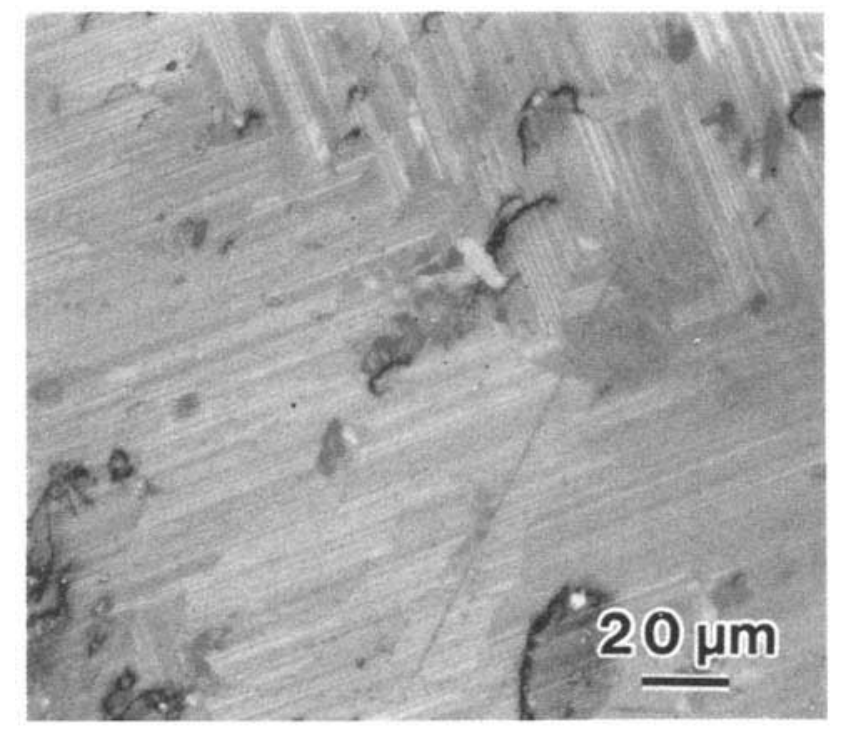

Fig. 18. Microstructure of MPMG processed YBaCuO sample with 123 stoichiometric composition. Note that no 211 inclusions exist in the sample. 
438 M. Murakami

On p. 178

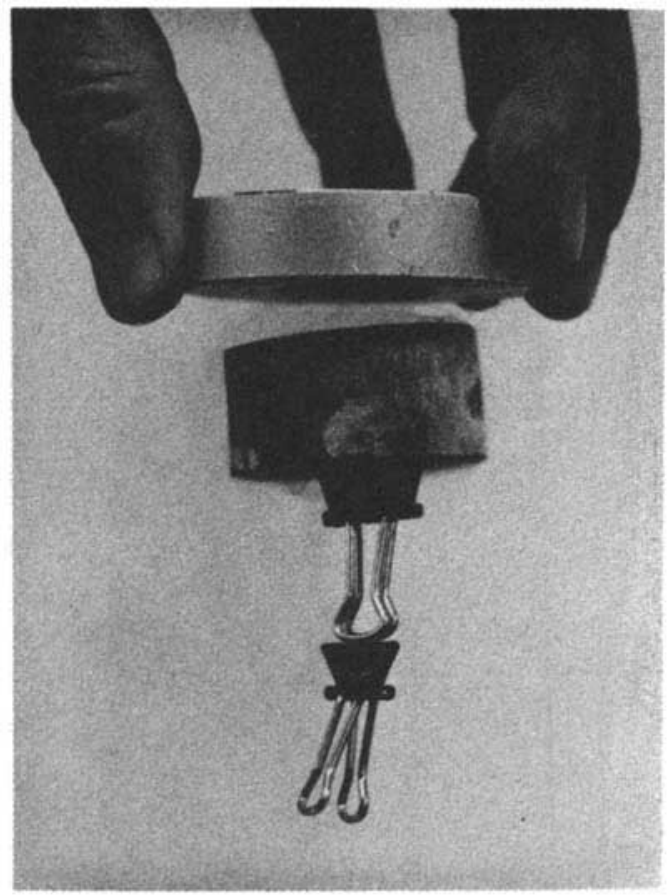

Fig. 19. A large disk sample fabricated by the MPMG process is suspended below an $\mathrm{Fe}-\mathrm{Nd}-\mathrm{B}$ magnet and attracting iron clips. 